الدباغ: التخصيص الامثل للمياه الفصلية بين مجموعة محاصيل تحت محدودية توفر مياه الري

التخصيص الامثل للمياه الفصلية بين مجموعة محاصيل تحت

محدودية توفر مياه الري

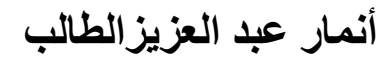

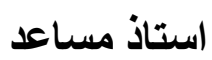

عبد الستار الدباغ إيمسان حسازم شـيت

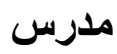

(ستاذ

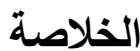

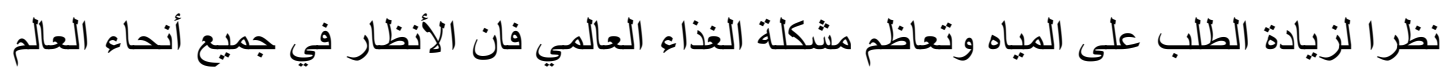

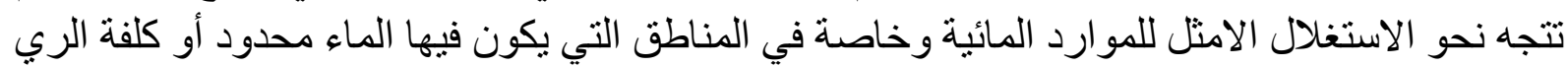

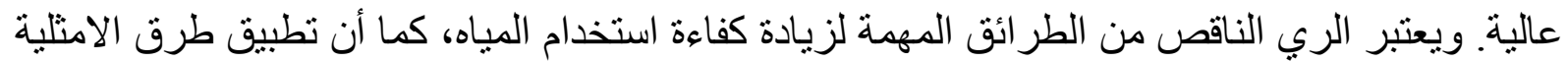

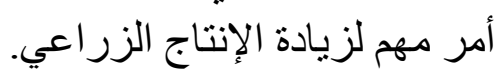

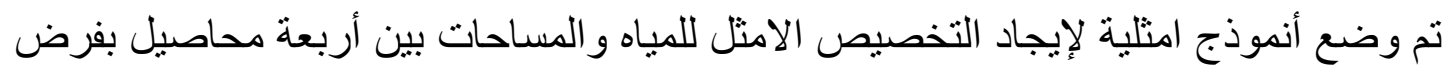

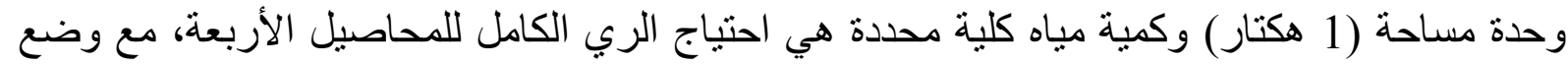

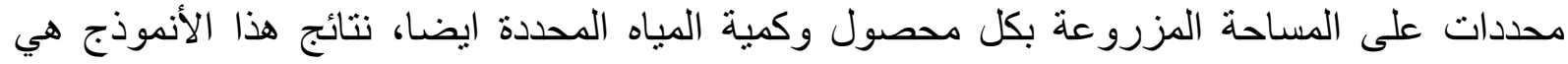

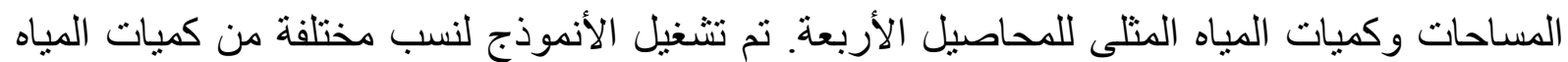

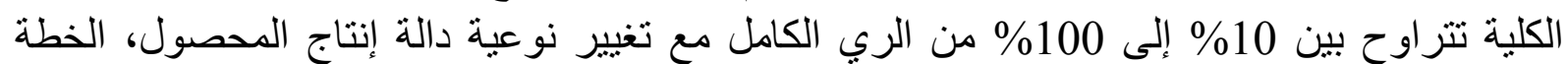

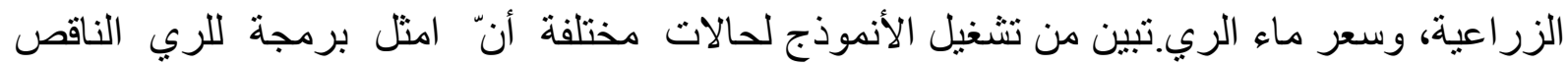

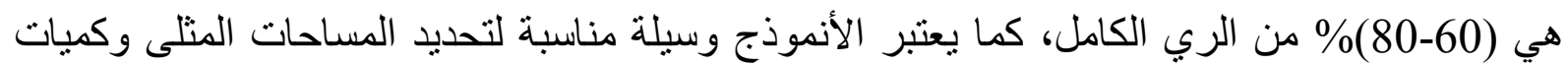
المياه المثلى لزيادة العائدات الاقتصادية.

الكلمات الدالة: امثلية الارواء، البرمجة غير الخطية، محدودية توفر مياه الري، تخصيص المياه لمجموعة محاصيل

Optimal Multicrop Allocation of Seasonal Water

Under Limited Irrigation Water
Abdul-Sattar Al-Dabagh
Eman Hazim Sheet
Anmar Al-Talib
Professor
Lecturer

\section{Assistant professor}




\begin{abstract}
As water demand is increasing and the world food problem is becoming more pronounced، world efforts are forwarded towards the optimal usage of water resources' specially in regions where water is scare or irrigation is very costly. Inadequate irrigation is considered one of the methods that increase water usage efficiency and the application of optimization methods is essential in order to increase agriculture production.

A mathematical model was developed for optimal allocation of irrigation water under full and inadequate irrigation. The model determines the optimal seasonal allocation of irrigation water between crops. The output of the model are the area and water allocated for each crop under limited and full irrigation. the effects of various management options ' as changing the plan of agriculture، type of production function' and value of irrigation water were studied. The model was run for many percentages of full irrigation ranging from $10 \%$ to $100 \%$. The model is considered a good approach for deciding on area and amount of irrigation water which achieves optimal values in irrigation planning projects under limited water resources.
\end{abstract}

Keywords: irrigation optimization, nonlinear programming, limited irrigation water, water allocation for different crops.

\footnotetext{
قبل في 2007/11/8 أستلم في 2007/1/28 المقدمة

تتجه معظم البحوث في الوقت الحاضر نحو التقنيات والطر ائق التي توفر الاستخدام الامثل للمياه. ويعتبر

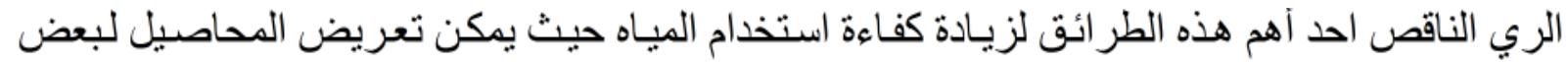

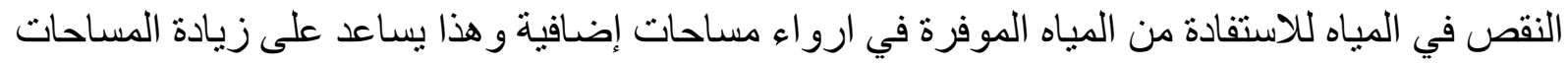

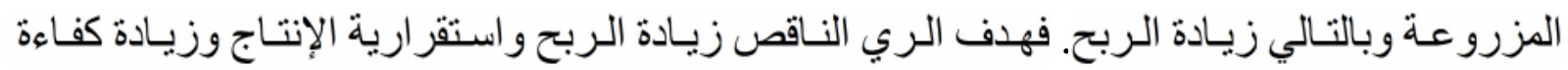

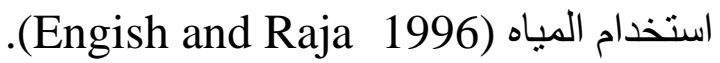


عندما تكون كميات المباه كافية لري مجمو عـة محاصبل ضـمن منطقة زر اعبـة معينة فليس هنالك يث بزود كل محصول باحتياجاته القصوى للحصول على أعلى إنتاج لوحدة المسـاحة.

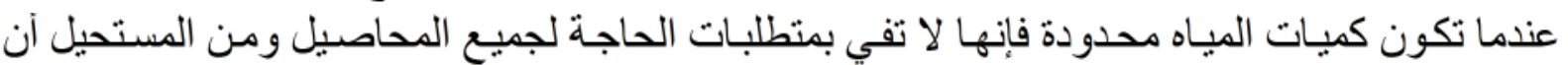

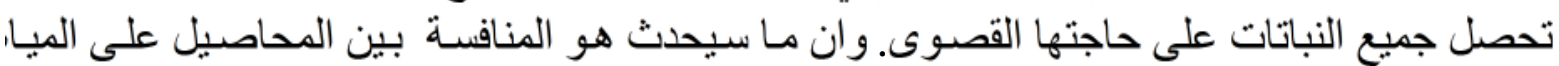
ولذا يجب أن نطبق مـا بسمى بنظـام الحصص (Water allocation process) لزيــادة الربـح. نماذج الحلول المثلى التي يمكن استخدامها في تخطبط الري النـاقص هي البرمجـة الخطبة أو اللاخطية.

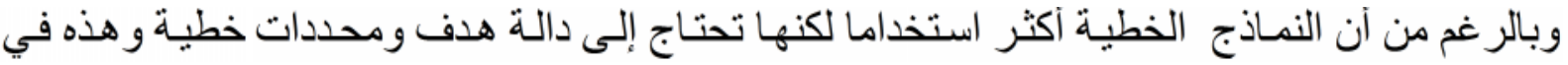

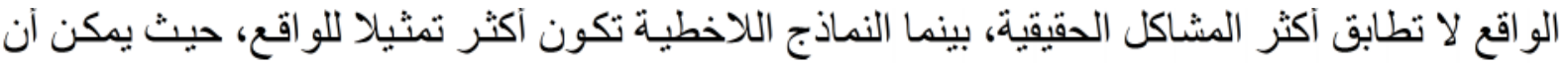
نحصل منها على نتائج آدق بدلا من تحويل الدالات اللاخطية إلى دالات خطية (2003 , Benli and Kodal

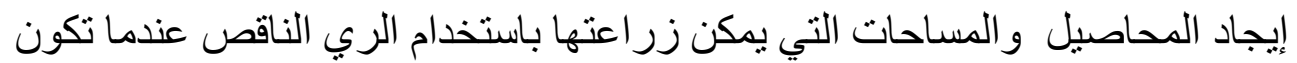
مصادر المياه غير كافية .

إن التوزيع الامثل للمباه الفصلية و على مر احل النمو ضمن الفصل الو احد درست بصـورة محدودة Dudly et al.(1971,a,b)

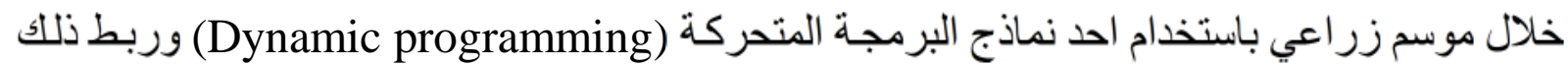

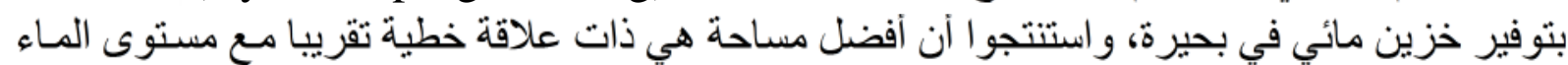

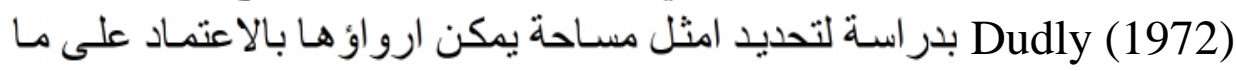
يمكن توفيره من خزين مائي بدالة تهدف إلى تعظيم العائد الاقتصادي. Al-Kazzaz(1977) در اسة تهدف الى تعظيم العائد الاقتصادي بموجب المعلومـات المتوفرة

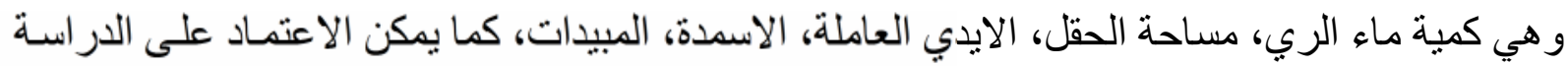
في تخمين العائد الاقتصادي ومقديه مقار الانتاج.

Bras and Cordova (1981)

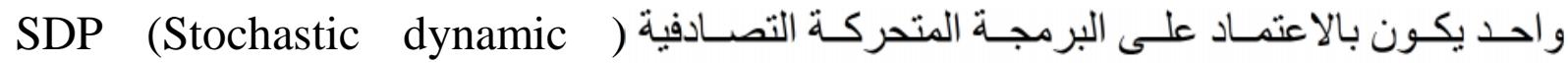

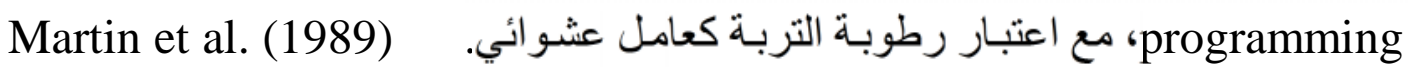

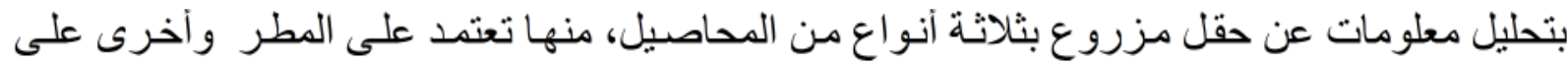
DDP (Deterministic dynamic programming) الري، واستخدموا البرمجة المتحركة لايجاد امثل توزيع للمياه و المساحات لمجمو عة من المحاصبل المرويـة وغير المرويـة على مدى خمس سنو ات، ووجدوا آن آفضل نسبة من المسـاحة المرويـة تغيرت من وامثل عمق للري الناقص تغير من $65 \%$ 65وان

يعد (1990) أهم من وضع أسس تخصيص المياه المحددة لأغر اض الري لمجموعة

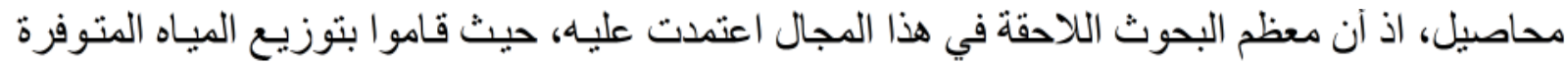
بين محصولين و التوزيع كان فصليا وضمن الفصل الواحد باستخدام البرمجة المتحركة المحددة (DDP) وباعتمـاد معـاملات اقتصـادية، المسـاحات المزروعـة، وحساسية النبـات للميـاه خـلال المر احل المختلفة، 
الدباغ: التخصيص الامثل للمياه الفصلية بين مجموعة محاصيل تحت محدودية توفر مياه الري

وبالاعتماد على دالات الإنتاج، وكانت النتائج النهائية هي التخصيصات الاروائية الأسبو عية. لم يستخدموا

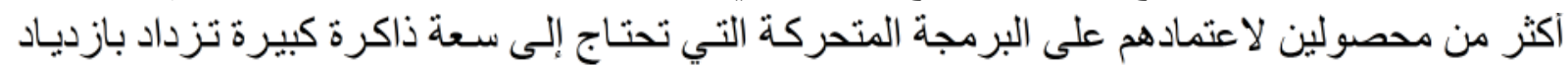

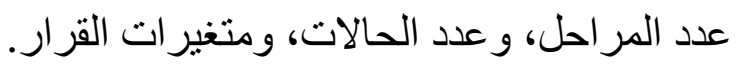

Francesco and Mecarelli (1994)

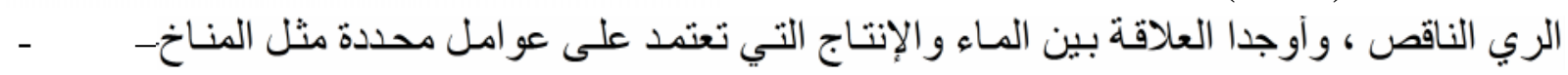
(Simulation model)

هذه المعادلة تتغير من سنة إلى أخرى. هذه العلاقات صيغت بشكل آنموذج رياضياتي مـع محددات بدالة

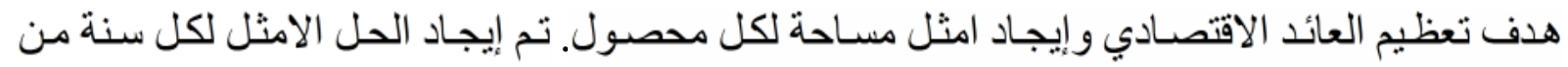

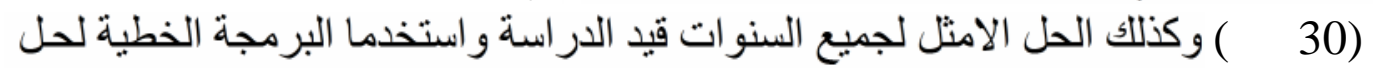
الأنموذج مع ملاحظة أن القيمة القصوى بالبرمجة الخطية تتحدد بأحد المحددات.

Kumar et al. (1998)

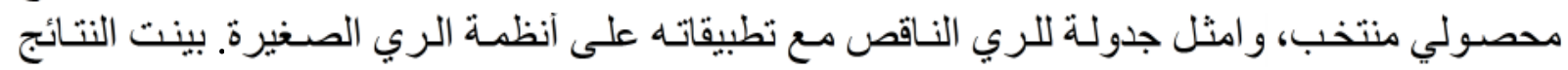

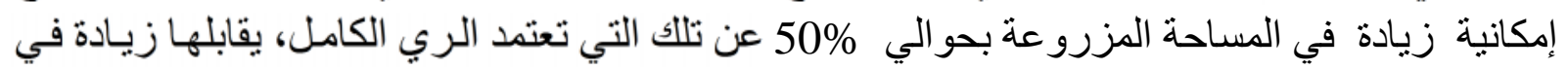

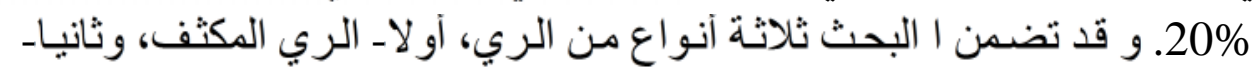

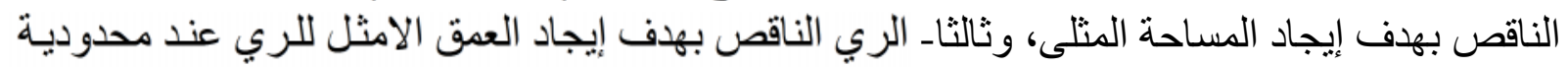

طaul et al. (2000)

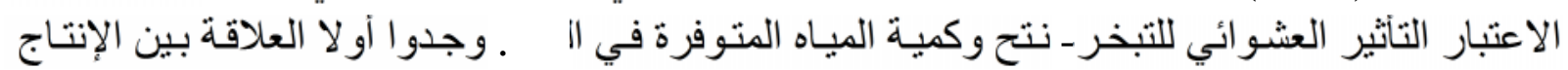

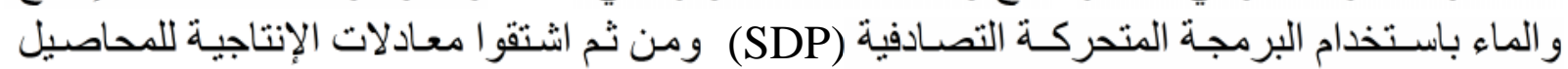

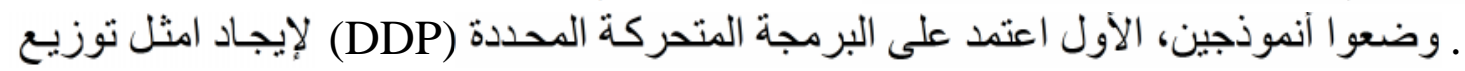

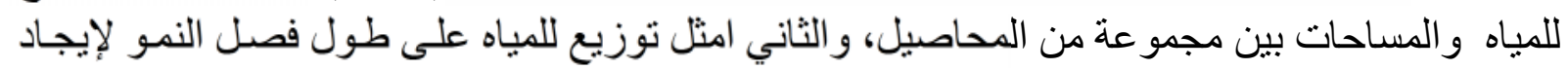
كميات الارو اء المثلى .

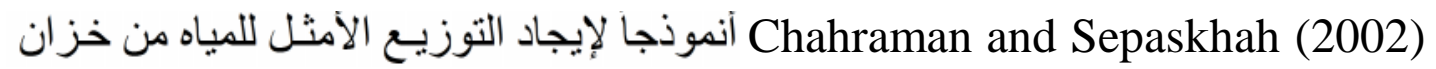

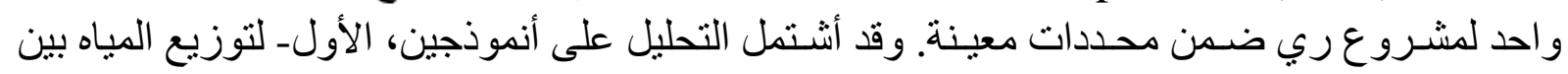

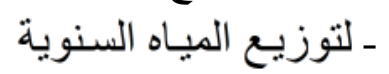

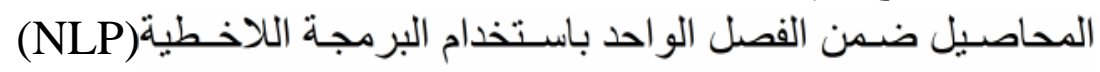

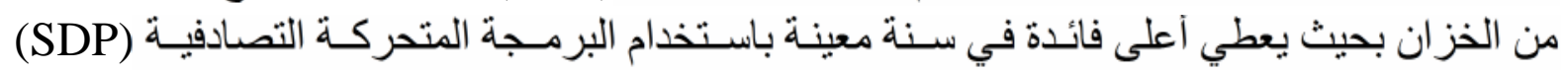

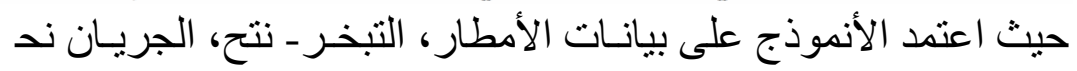

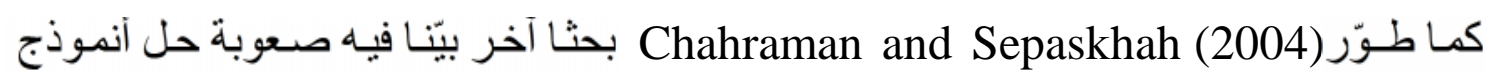
و احد متكامل، وفيه جميع المتغير ات مع إدخال مجمو عة من المحاصيل، ويثابه الو اقع باستخدام البرمجة المتحركة بسبب مشكلة الأبعاد وحاجته إلى وقت أطول في التنفيذ وخزن اكبر في الذبـ الذاكرة.

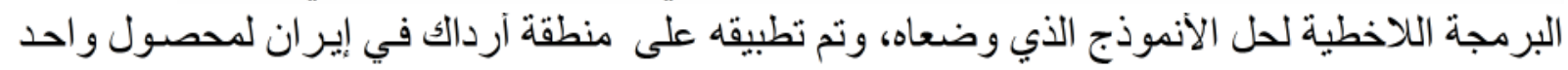
ولمجمو عة محاصيل (حنطة،شعير ،ذرة،قصب التصب السكر ). 


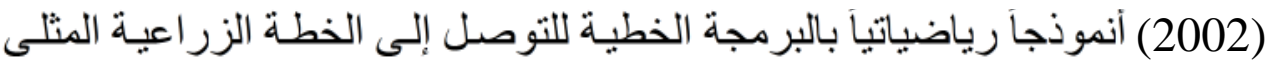

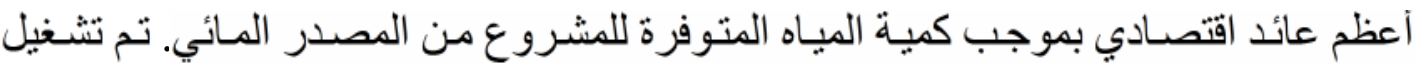

الأنموذج الرياضياتي على ثلاثين حالة تختلف كل واحدة عن الأخرى بنقطتين أساسيتين، هـا محددات

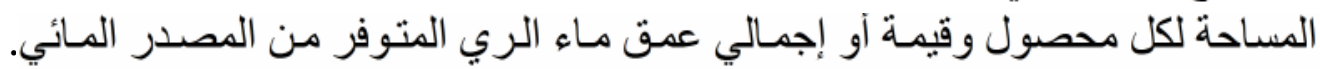

تحديد النسبة المئوية لزر اعة كل محصول ضمن الخطة الزر اعية المعتمدة تمثل النتائج المثلى في تحقيق المن

Benli and Kodal (2003)

Ms-Excel solver)

بدالة هدف تعظيم العائد الاقتصادي ت

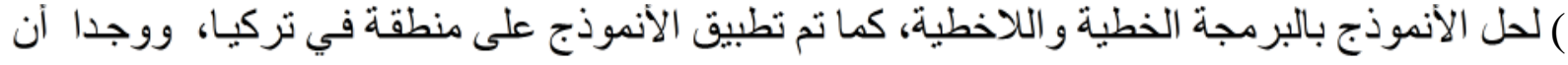
الأنموذج اللاخطي يعطي عائدات اكبر تحت ظروف الري الرئه الناقص.

Gorantiwar and Smout (2003)

المناوبات، مع استخدام الري الكامل و الناقص، ووجدا ان الري الناقص يزيد المساحة بمقدار 30\%-45\%

40\%-20\% مع العلم أن هذه النسب تتغير بتغير نوع التربة.

Gorantiwar and Smout (2005)

بالاعتماد على عمق ري متغير عند محدودية توفر المياه مع تطبيق الدورة الزر اعية آخذين بنظر الاعتبار

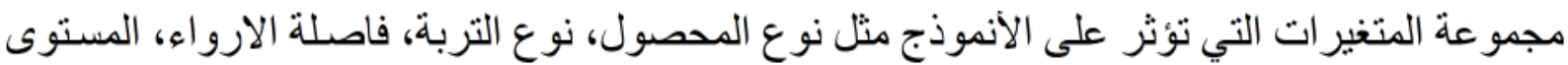

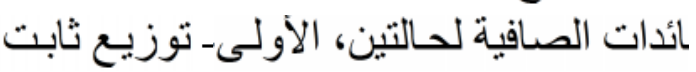

للمحاصيل، و الثانيةـ توزيع متغير، مع تحليل الحساسية ووجدا آن العائدات بفرض عمق الري المتغير \%22 \%مّا هو موجود.

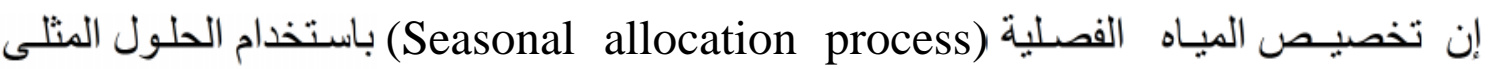
وبهدف زيادة الربح يعني إيجاد امثل مساحة و إعطاء آفضل كمية مياه لتلك المساحة بهدف زيـادة العائدات الكلية للحقل ضمن المحددات.

\section{طر ائق ومواد البحث}

\section{الأنموذج الرياضياتي:}

إن فكرة هذا الأنموذج هي: اذا كانت لدينا كميـة محدودة من المبـاه في بدايـة السنة وارددنـا

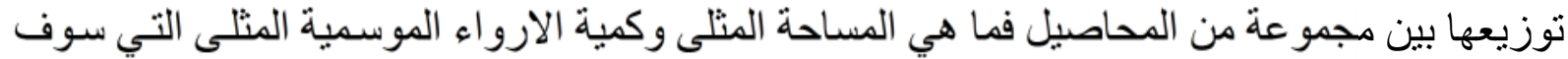

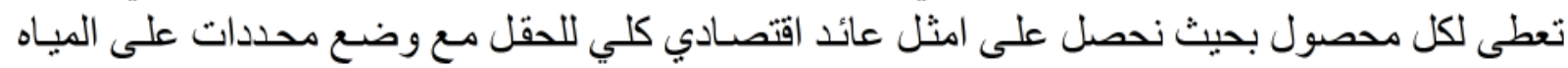
ـ تمت صياغة الأنموذج بوضع دالة الهدف مع المحددات كالآتي:

دالة الهدف:

$$
M A X \quad N B=\sum_{i=1}^{n c} A_{i}\left[B_{i} Y_{i}-C_{i}\right] .
$$




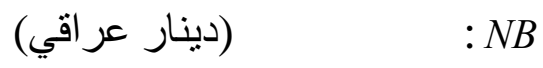

$$
\begin{aligned}
& \left(\begin{array}{llll}
=4 & =3 & =2 & =1
\end{array}\right) \quad: i \\
& \text { (4c) مؤشر لعدد المحاصيل (nc) } \\
& \text { (هكتار) } \quad: A_{i} \\
& \text { Bi }
\end{aligned}
$$

Cلفة الإنتاج وتشمل أسعار البذور والأسمدة والخدمة والآلات بالإضـافة إلى مياه

$$
\text { ( دينار عر اقي/هكتار ) }
$$

～: $\quad$ ويمكن التعويض عنه بدالة إنتاجية المحصول.

$$
Y_{i}=\frac{Y_{a c t}}{Y_{\max }}=f\left(X_{i}\right)
$$

$$
\begin{aligned}
& \text { Y Yact }
\end{aligned}
$$

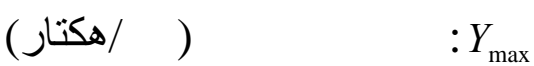

$$
\begin{aligned}
& \text { ( ) } i \quad: X_{i} \\
& \text { i f(X }{ }_{i} \text { : دالة إنتاجية المحصول }
\end{aligned}
$$

إن دالة إنتاجية المحصول تعبر عن العلاقة بين الإنتاج النسبي و عمق الإرواء الموسمي، لقد تم

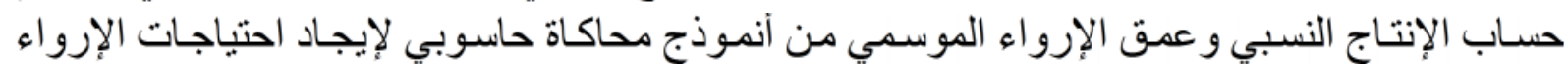

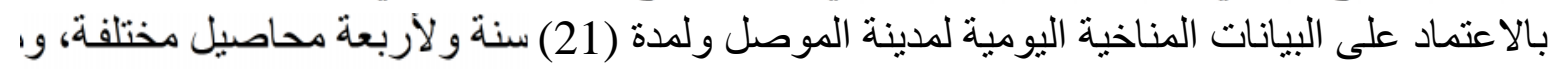
ثم تم ربط العلاقة بين الإنتاج النسبي وعمق الإرواء الموسمي باستخدام برنامج إحصائي (شيت 2006).

$$
\text { 1أما المحددات فهي: }
$$


) محدد المياه الكلية المتوفرة في بداية السنة:

$$
\begin{aligned}
& 10 * \sum_{i=1}^{n c} X_{i} A_{i}<=p Q \\
& \text { ) محددات المياه لكل محصول: }
\end{aligned}
$$

$$
\begin{aligned}
& X_{i}<=X_{\text {max }, i} \\
& X_{i}>=X_{\text {min }, i}
\end{aligned}
$$

$$
\text { : }
$$

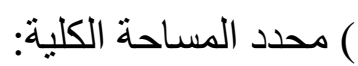

..(6) $\sum_{i=1}^{n c} A_{i}<=1$

$A_{i}<=A_{\text {max }_{i}}$

$A_{i}>=0$

Q

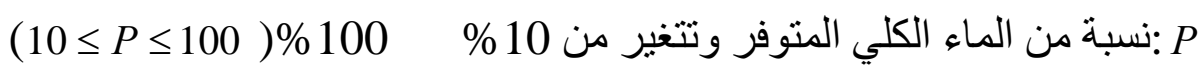
( ) $i$
$: X_{\max , i}$
( ) $i$
$: X_{\min , i}$

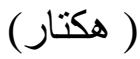
$: A_{\text {max }, i}$ 


\section{تطبيق الأنموذجـ: تم تطبيق الأنموذج لكل من الحالات التالية:}

$$
\text { 2) }
$$

3) تم تغيير سعر ماء الري من (70) دينار عر اقي / 3 (100 150 ) دينار عر اقي / 3.. إن قيم

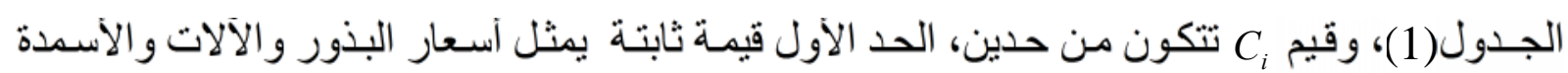

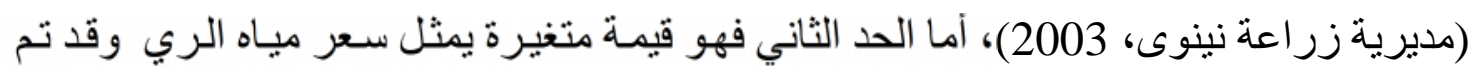
تقديره حسب النعيمي و شديد (2006) .

(1): الاسعار المعتمدة لمجموعة المحاصيل

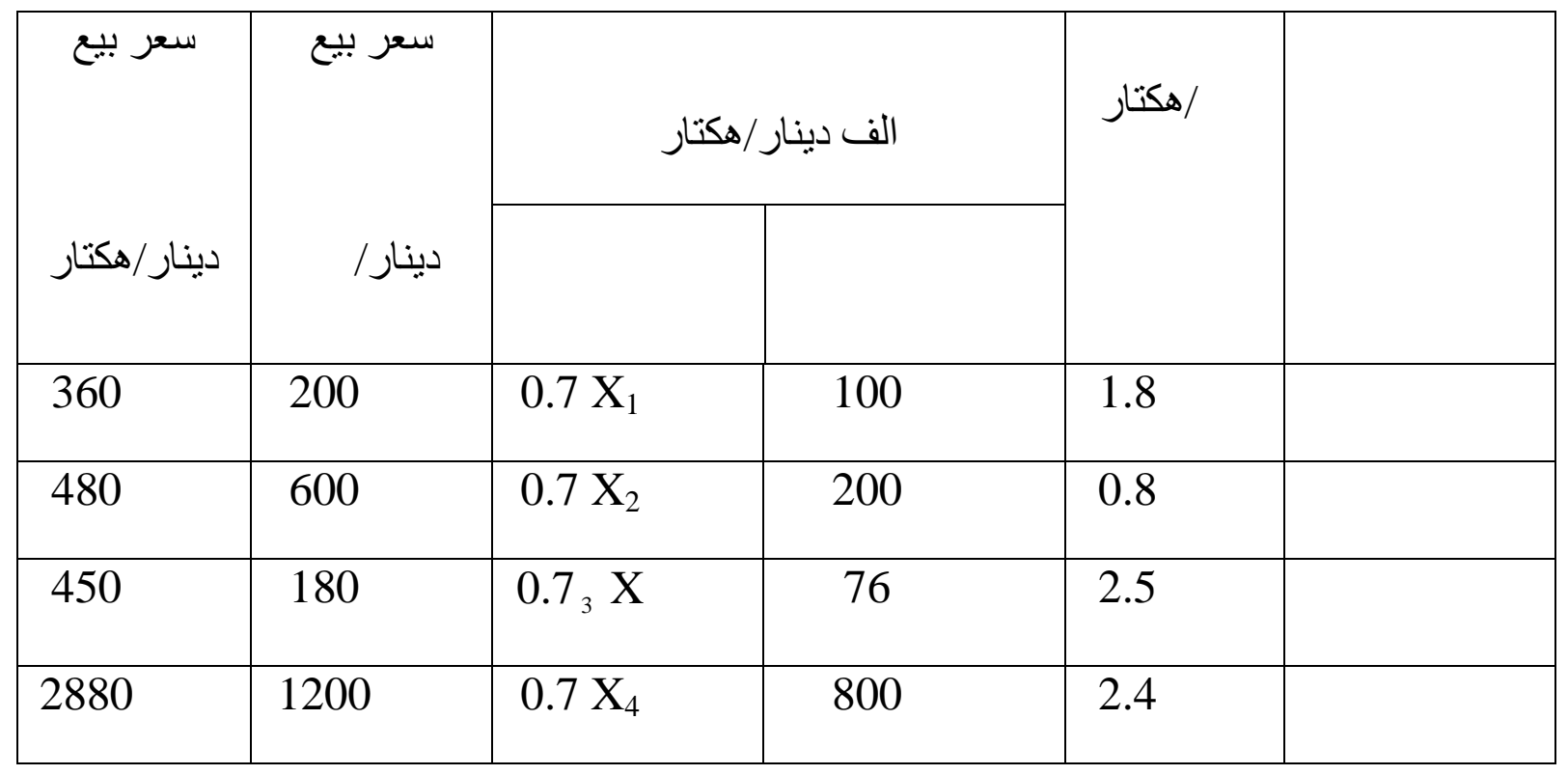

$\begin{array}{ll}\text { ( ) } & : X_{1} \\ (\quad) & : X_{2} \\ (\quad) & : X_{3}\end{array}$




$$
\text { ( ) } \quad: X_{4}
$$

ان قيم $\left(X_{\text {max }, 4}, X_{\text {max }, 3}, X_{\text {max }, 2}, X_{\text {max, }}\right.$ )، التي هي(530,315,150,215) ملم، والتي تمثل احتياج

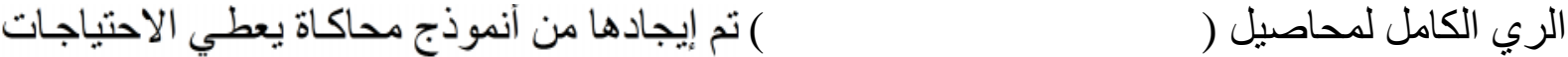

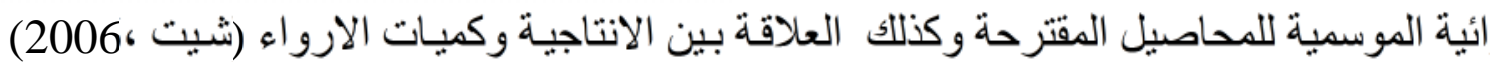

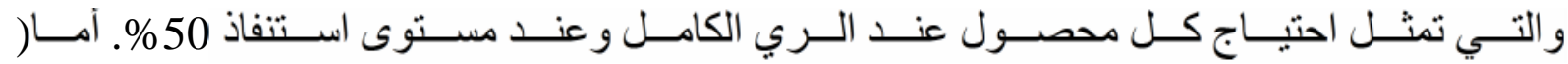

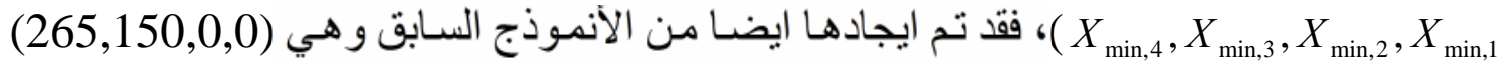

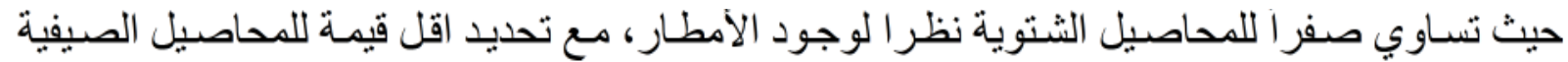

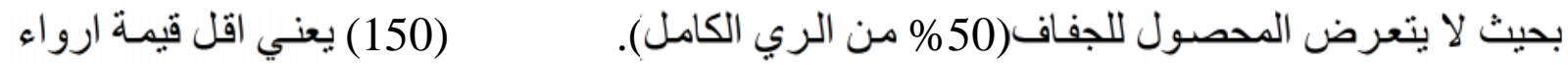

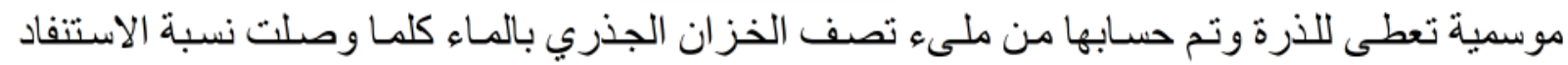
50\%. أما قيمة (Q Q و فهي كمية محدة من المياه متوفرة في بداية الموسم حيث تم تشغيل

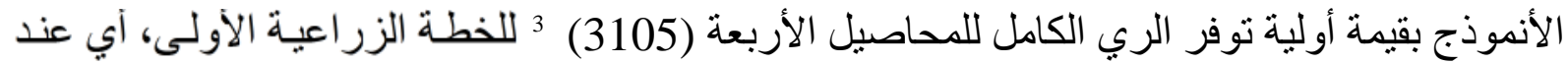

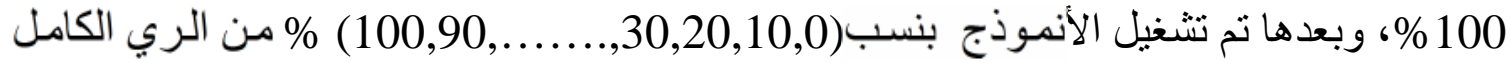

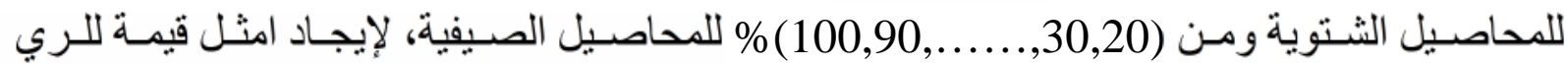

تم فرض مساحة كلية تساوي (1هكتار) لزر اعة المحاصيل الأربعة، أمسا المساحة المزروعة بكل

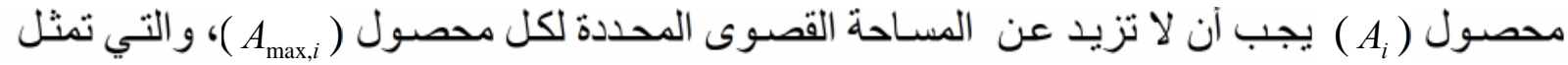

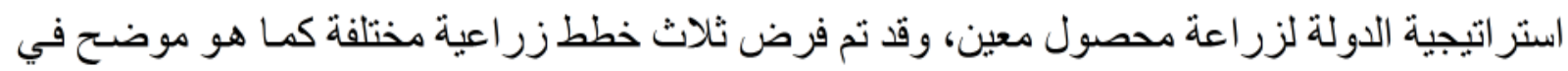

$:(2)$

\begin{tabular}{|l|c|c|c|c|}
\hline & & & & \\
& & & & \\
& & & & \\
& & & & \\
\hline 0.25 & 0.2 & 0.05 & 0.5 & \\
\hline 0.4 & 0.25 & 0.15 & 0.6 & \\
\hline 1 & 1 & 1 & 1 & \\
\hline
\end{tabular}




\section{النتائج و المناقشة}

دالـة إنتاجية المحصول: تم استخدام دالتين للإنتاج، دالة خطية ودالـة تربيعيـة (شيت،2006).

و المعادلات التالية تبين الدالات المعتمدة في الانموذج:

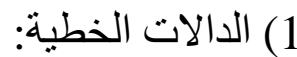

$$
\begin{aligned}
& Y_{1}=0.57+1.57 * 10^{-3} X_{1} . \\
& Y_{2}=0.68+1.47 * 10^{-3} X_{2} \\
& Y_{3}=0.058+8.8 * 10^{-4} X_{3} \ldots \\
& Y_{4}=6.46+8.8 * 10^{-4} X_{4} \ldots
\end{aligned}
$$

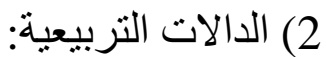

$$
\begin{aligned}
& Y_{1}=0.38+4.5 * 10^{-3} X_{1}-9.8 * 10^{-6} X_{1}^{2} \ldots \\
& Y_{2}=0.72+7.1 * 10^{-4} X_{2}+3.9 * 10^{-6} X_{2}^{2} . \\
& Y_{3}=0.77+9.0 * 10^{-3} X_{3}-1.3 * 10^{-6} X_{3}^{2} \ldots \\
& Y_{4}=-0.28+4.2 * 10^{-3} X_{4}-3.8 * 10^{-6} X_{4}^{2}
\end{aligned}
$$

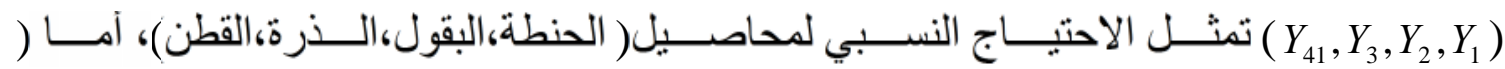

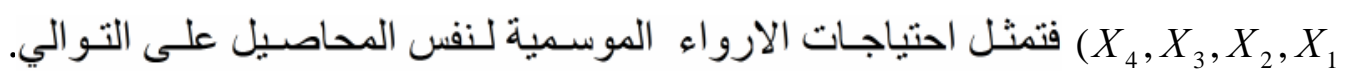

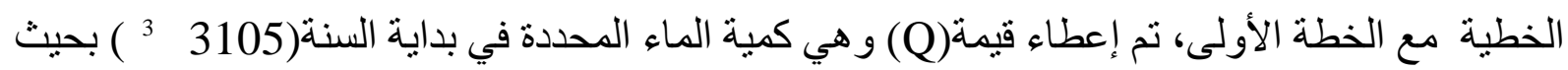

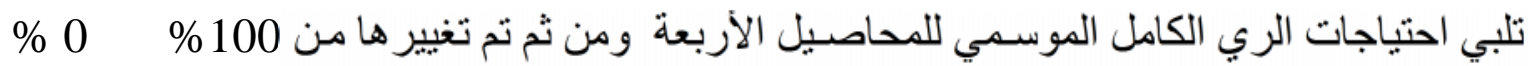

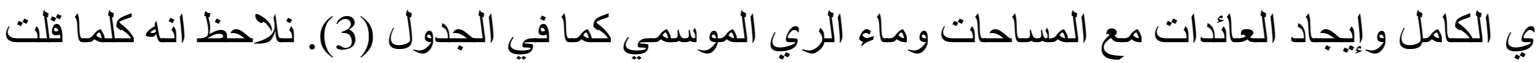

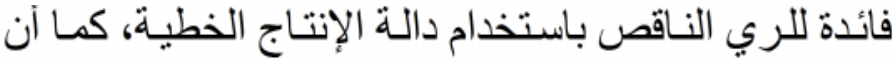

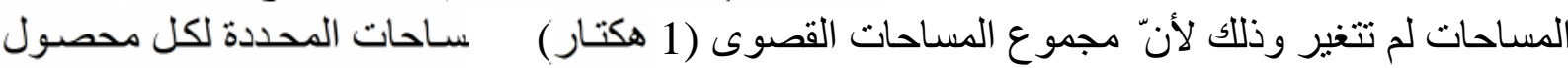




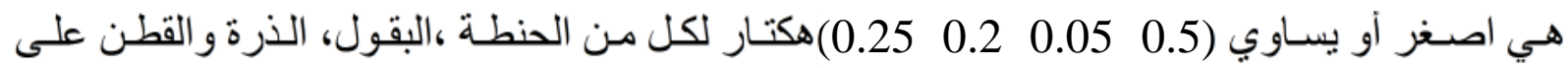
ـ وبما أن دالة الهذف هي تعظيم العائدات فسيتجه حل الأنموذج نحو المساو اة بدلا من الأصغر.

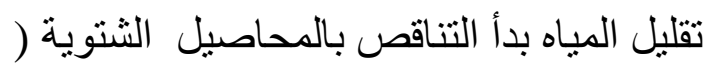
بالمياه إلى حد 70\% من الري الكامل و النقص كان اكبر للبقول من الحنطة لان الحنطة فائدتها آكثر ، كما

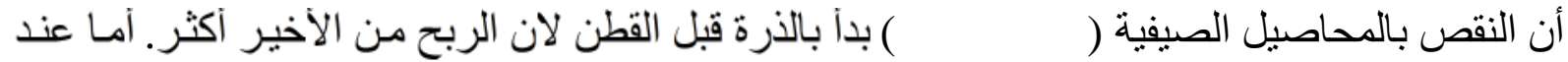

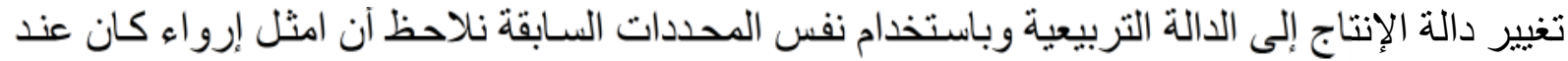

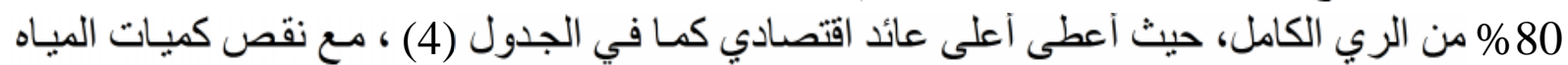

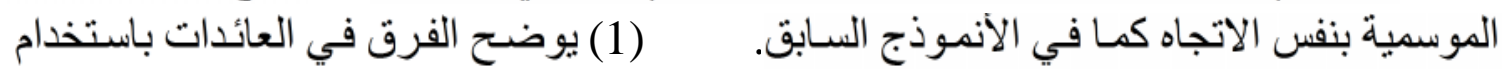

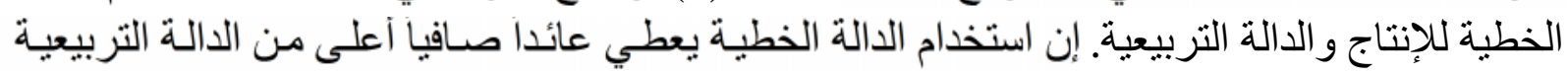
عند الري الكامل ونسبا مختلفة من الري الناقص، على سبيل المثنال عند نسبة إرواء (100)

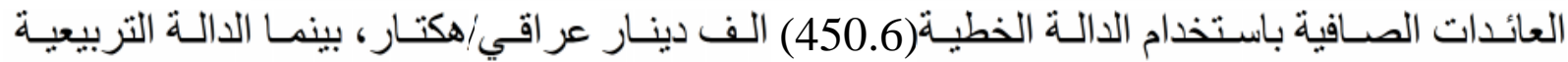

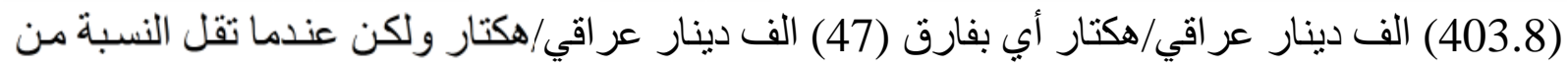

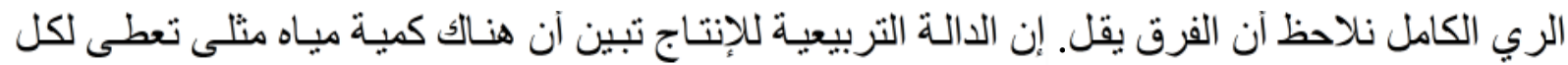

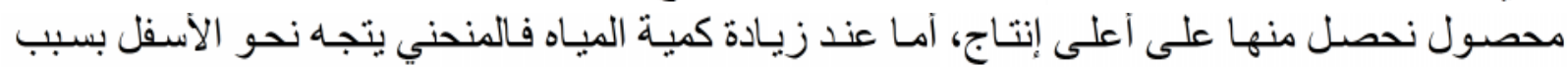

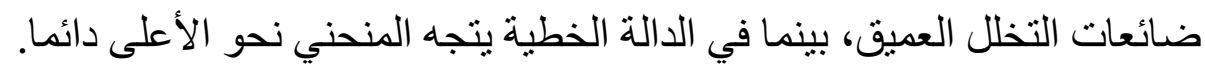

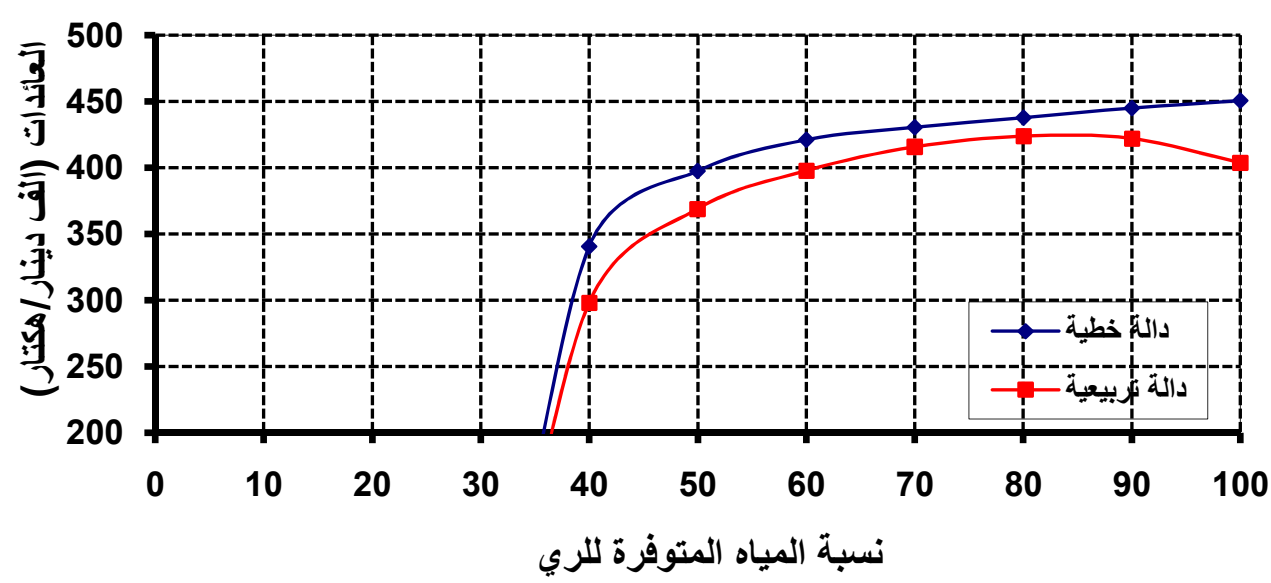

(1): (1) تغير العائد الصافي بتغيير دالة الإنتاج

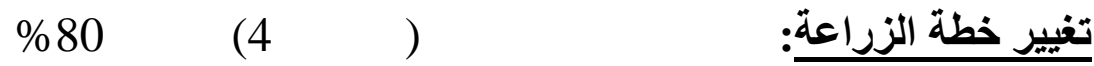

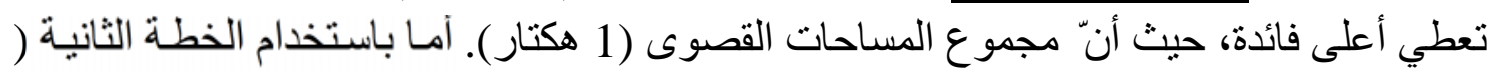


حيث المساحة القصوى للحنطة (0.6)هكتار و البقول (0.15) هكتار و الذرة (0.25) هكتار و القطن (0.4)

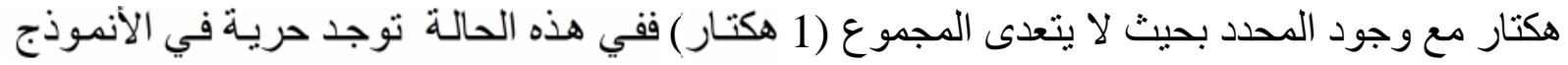

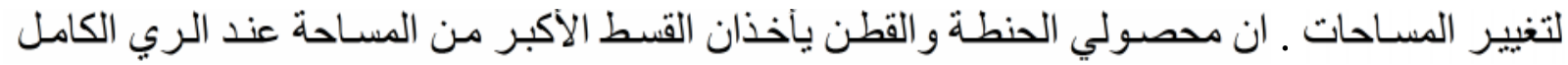
مانمان.

90 من الري الناقص، اما الفائدة او الربح فتكون اكبر ما يمكن عند 90\%

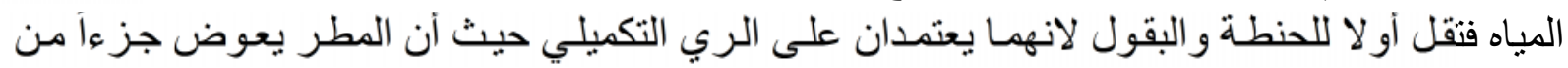

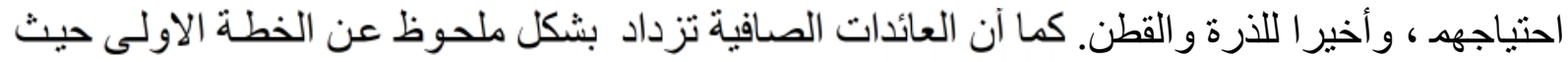
يتجه حل الأنموذج نحو زيادة مساحة المحاصيل التي تعطي عائداً اقتصادياً اكبر.

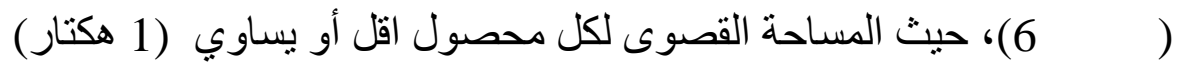

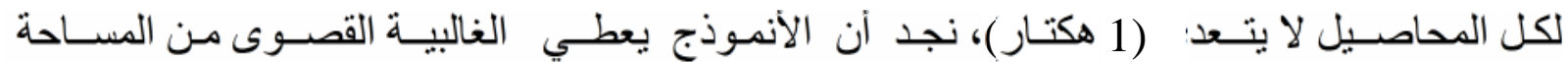

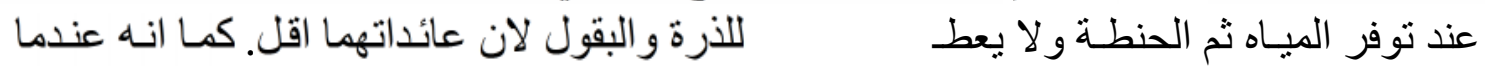

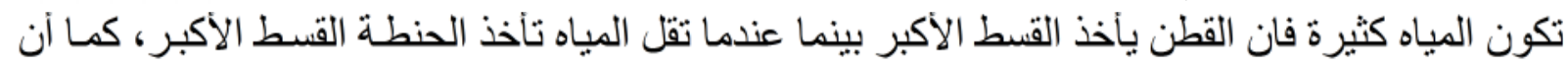

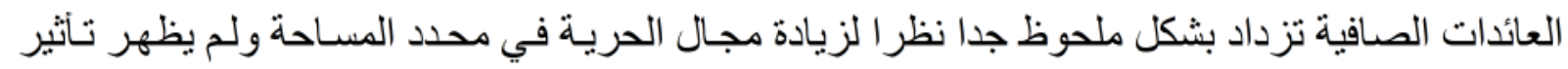
هذه الخطة. من هذا يتبين فائدة الري الناقص عند علد محدودية المساحة ، و والثكل ( 2) يبين

تغير العائدات الصافية بتغيير الخطة الزر اعية.

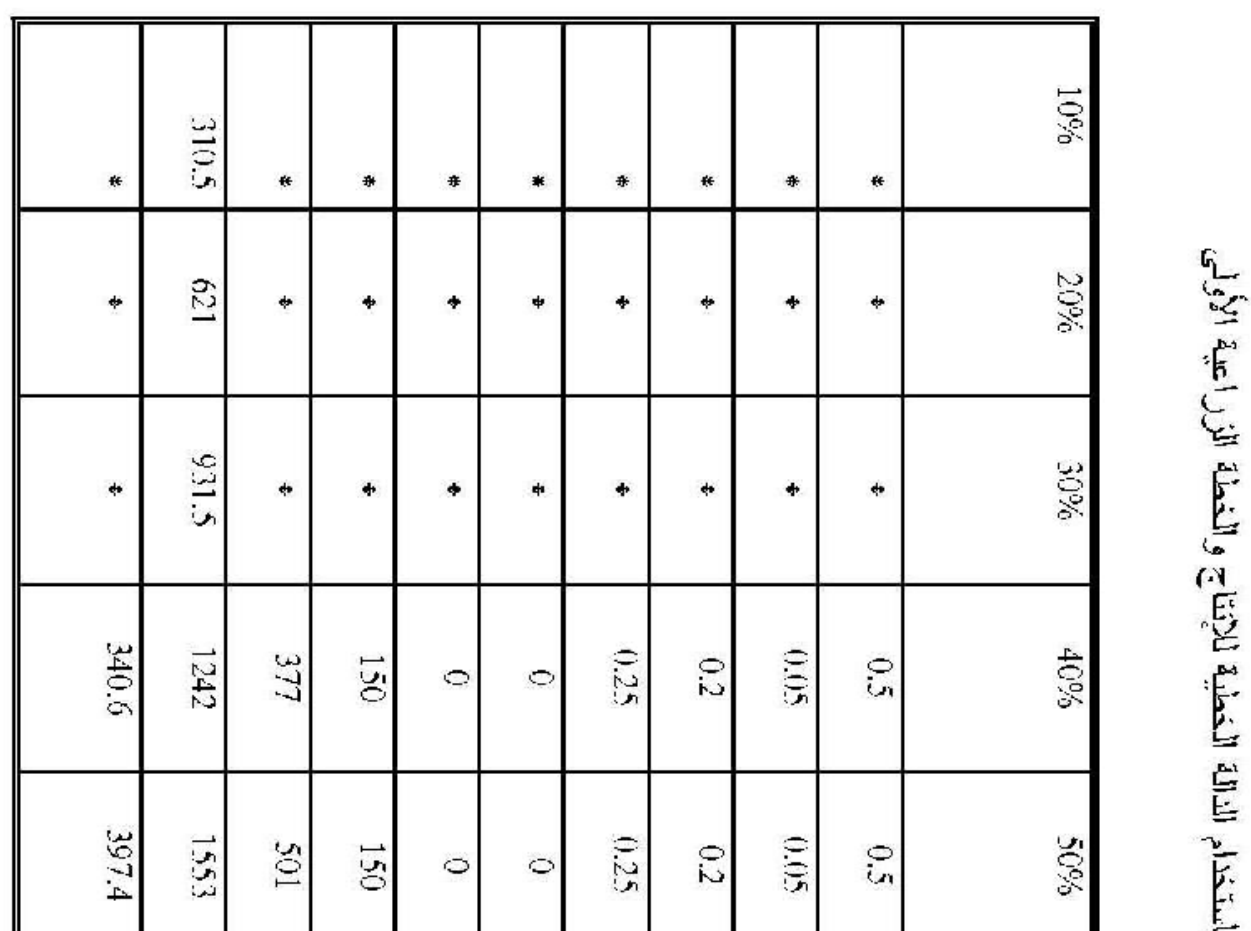


الدباغ: التخصيص الامثل للمياه الفصلية بين مجموعة محاصيل تحت محدودية توفر مياه الري 
الدباغ: التخصيص الامثل للمياه الفصلية بين مجموعة محاصيل تحت محدودية توفر مياه الري

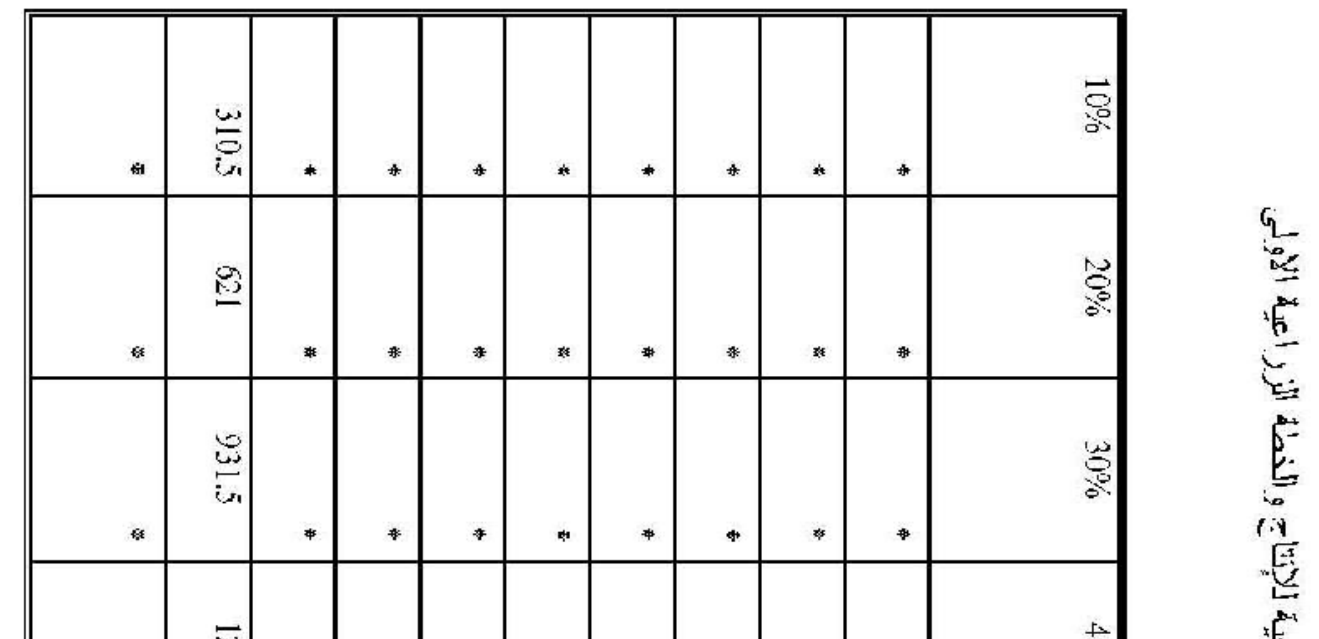


الدباغ: التخصيص الامثل للمياه الفصلية بين مجموعة محاصيل تحت محدودية توفر مياه الري 
الدباغ: التخصيص الامثل للمياه الفصلية بين مجموعة محاصيل تحت محدودية توفر مياه الري

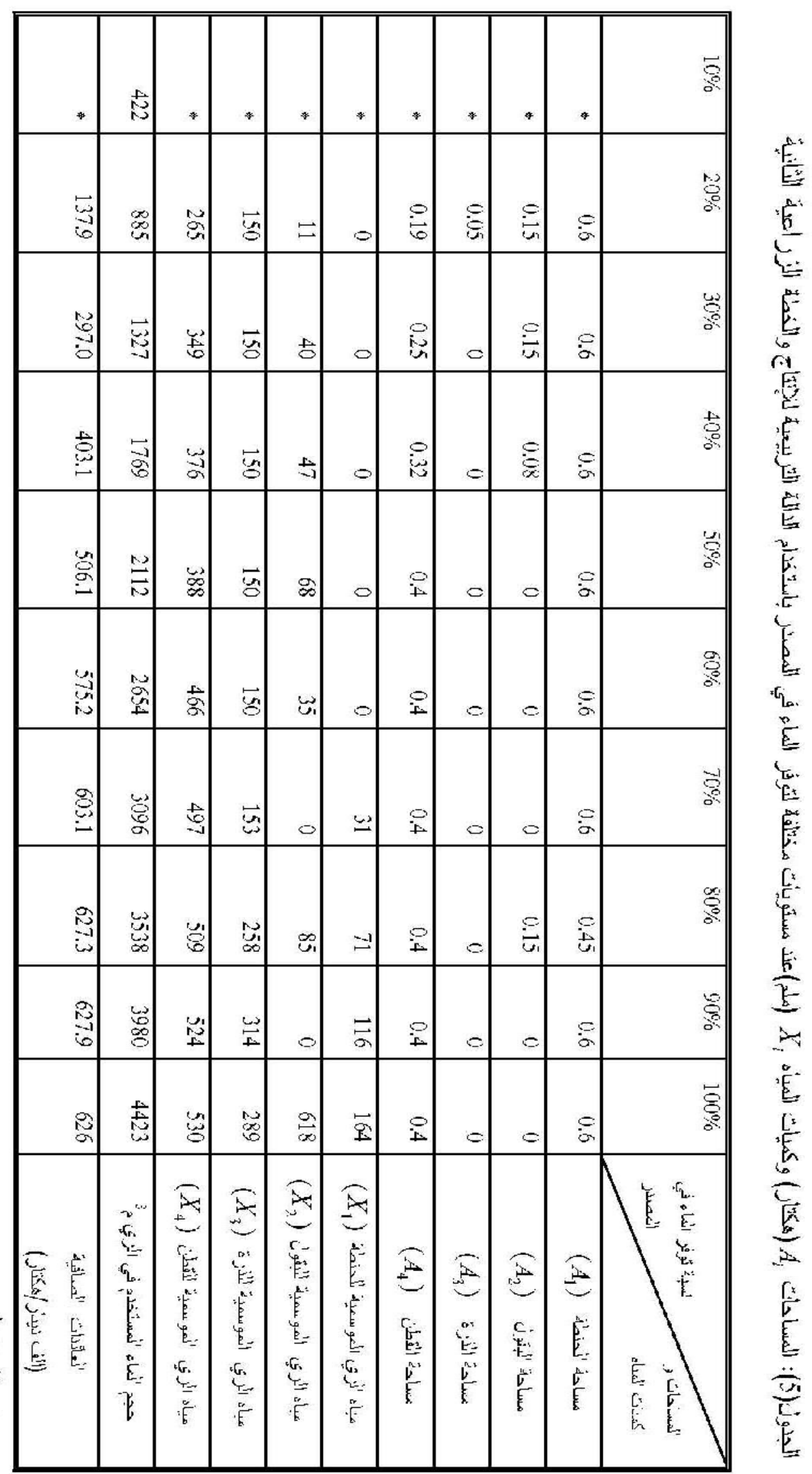


الدباغ: التخصيص الامثل للمياه الفصلية بين مجموعة محاصيل تحت محدودية توفر مياه الري 


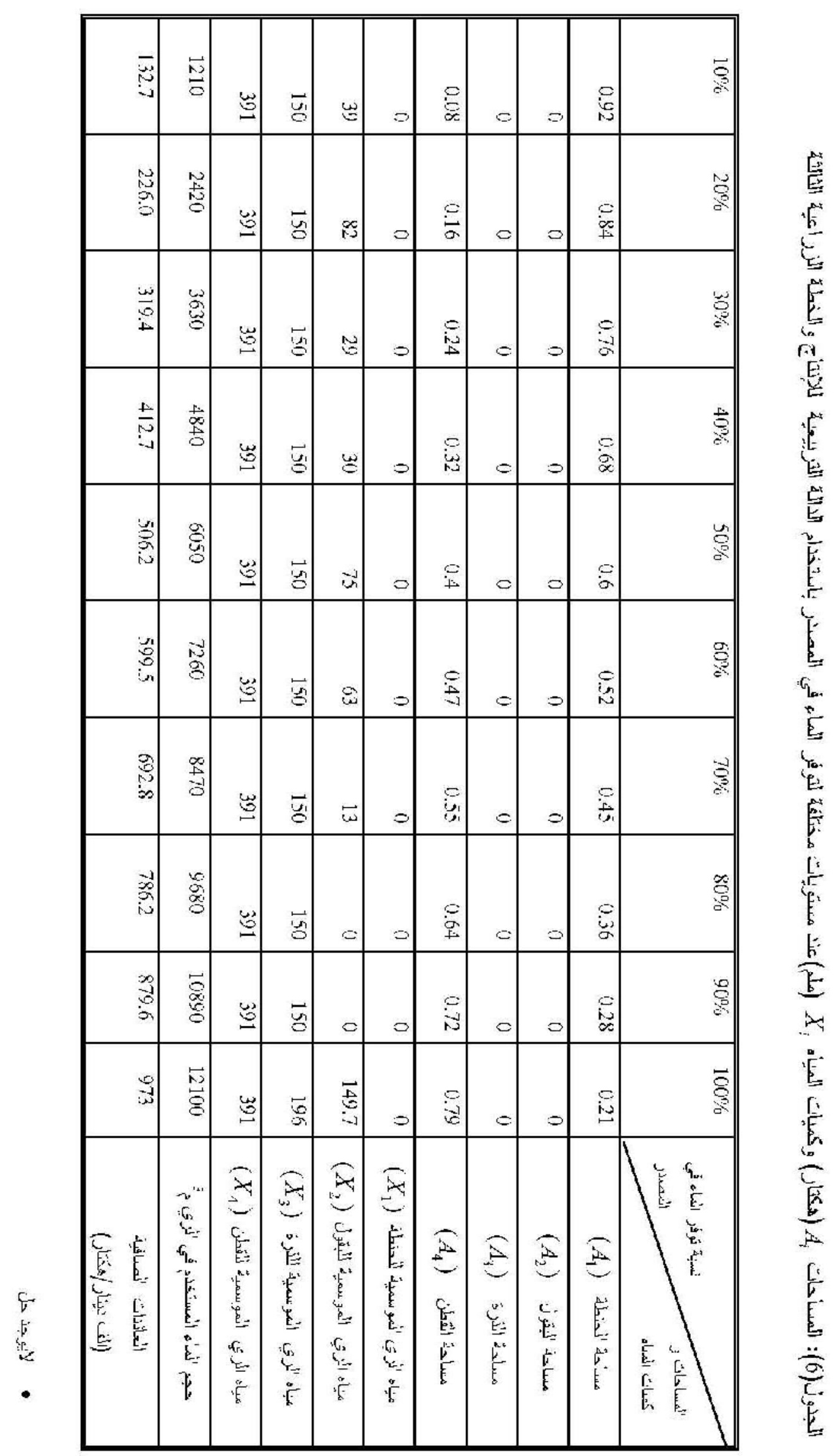


الدباغ: التخصيص الامثل للمياه الفصلية بين مجموعة محاصيل تحت محدودية توفر مياه الري 


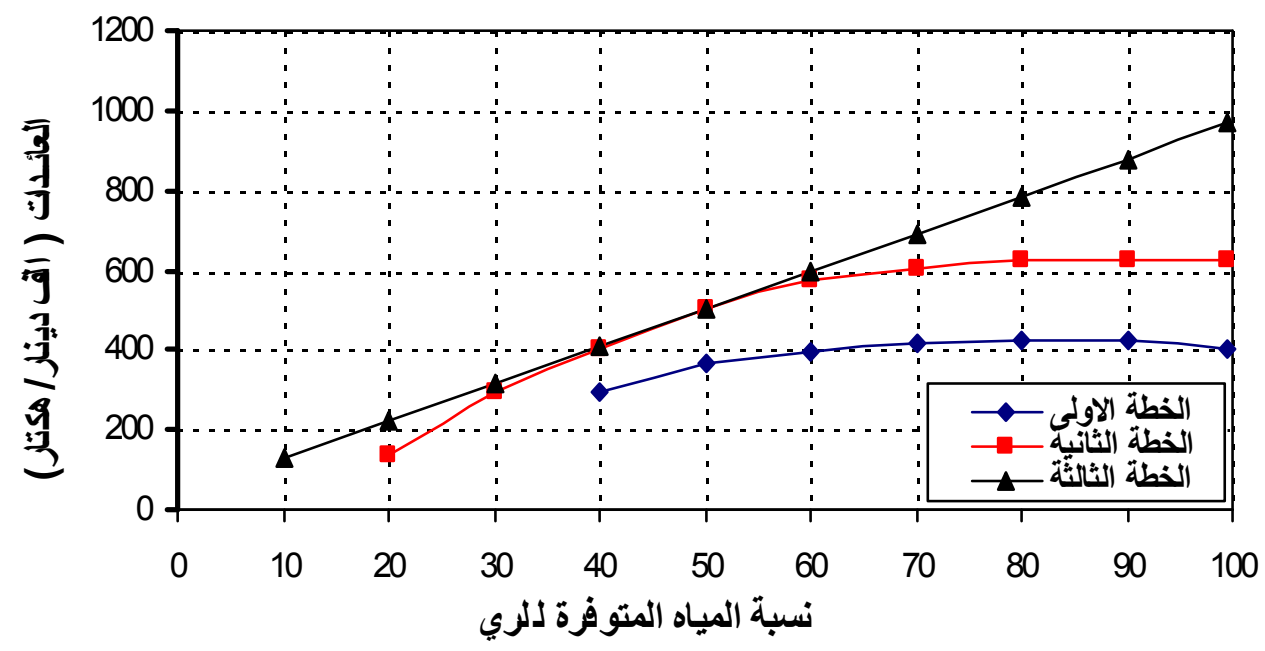

(2): تغير العائدات الصافية مع نسبة الارواء بتغيير الخطط الزر اعية

تأثير سعر مياه الري: (3) يبين تغير العائدات بتغيير سعر مـاء الري. نلاحظ في الثكل انهه عند

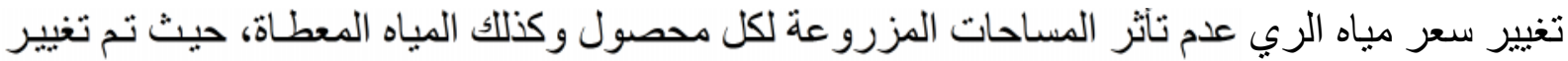

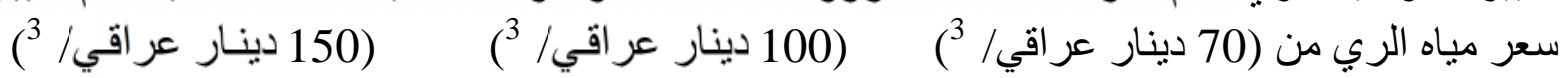

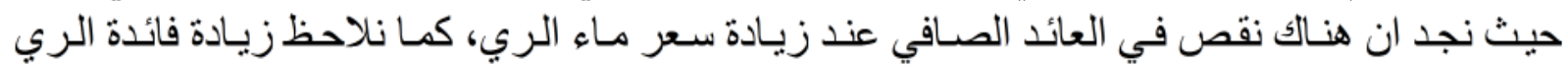

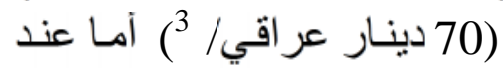
اقص حيث اعلى فائدة عند 880\% \%60\% \% \% (100)

(150 دينار عر اقي/ 3) ـ من هذا يتضح آن الري الناقص تكبر فائدته في المناطق التي يكون فيها سعر ماء الري مرتفعا، مع الأخذ بنظر الاعتبار أن زيـادة سـر مـاء الري يقلل العائدات

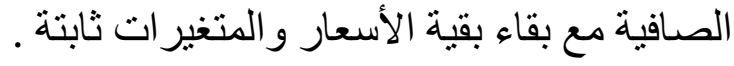


الاباغ: التخصيص الامثل للمياه الفصلية بين مجموعة محاصيل تحت محدودية توفر مياه الري

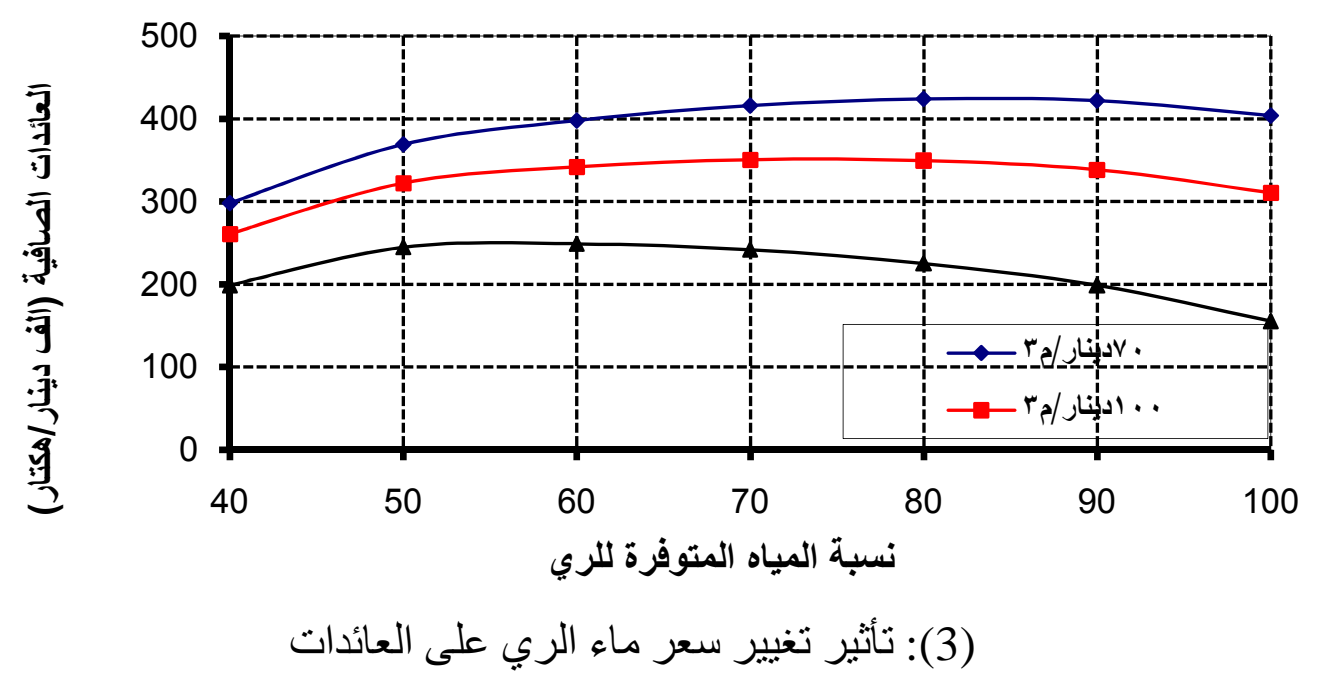

\section{الاستنتاجات}

إن النمذجة وسيلة مناسبة لغرض التوصل إلى كميات المياه المثلى و المساحات المثلى لكل محصول

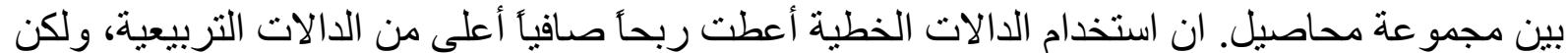

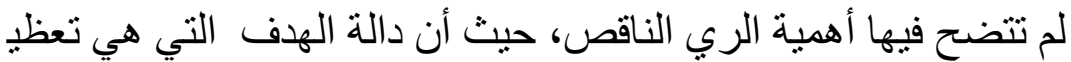

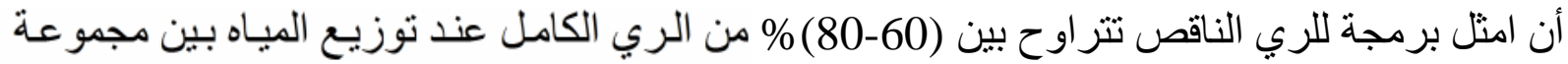

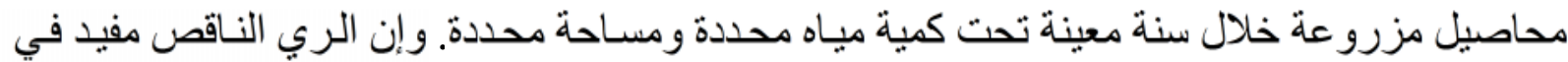

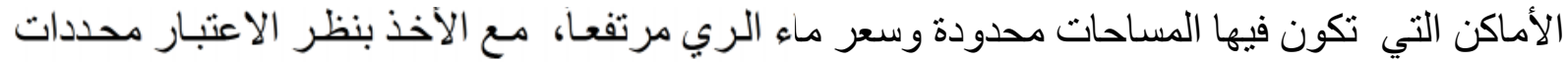

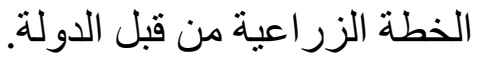

المصادر

- المصادر العربية:

عبد العزيز (2002) ."العائد الاقتصـادي الامثل عند تغير كمية مياه الري المتوفرة، .1

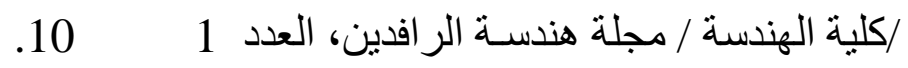

2. النعيمي، سالم يونس و كامل حايف شديد (2006) ." تحليل اقتصادي مقارن لأثر الري التكميلي في

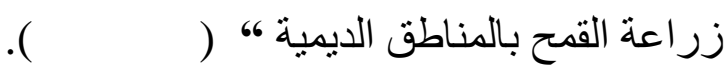

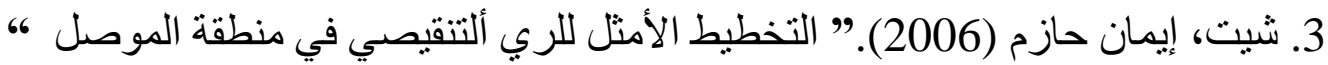
كلية الهندسة، قسم المو ارد المائية، جامعة الموصل.

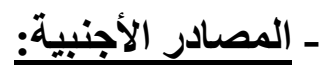


1. Al-Kazzaz، S. A. (1977). " Multiobjective optimization of farm irrigation system”. M.Sc. thesis ‘ Colorado State University، USA، P. 135.

2. Benli، B. and S. Kodal (2003). "A non linear model for farm optimization with adequate and limited water supplies: application to the south-east Anatolian project(GAP) region". Agriculture Water Management، 62: 187203.

3. Bras، L. R. and J. R. Cordova (1981). "Intraseasonal water allocation in deficit irrigation”. Water Resources Research، 17(4): 866-874.

4. Chahraman، B. and A. Sepaskhah (2002). "Optimal allocation of water from a single reservoir to an irrigation project with pre-determined multiple cropping pattern". Irrigation Science، 21: 127-137.

5. Chahraman، B. and A. Sepaskhah (2004). "Linear and non linear optimization models for allocation of a limited water supply". Irrigation and Drainage، 53(1): 39-54.

6. Doorenbos، J. and A. H. Kassam (1979). "Yield response to water". FAO Irrigation and Drainage Paper No. 33.

7. Dudley، N. J.، D. T. Howell and W. D. Musgrave(1971،a). "Irrigation planning 2: Choosing optimal acreages within a season". Water Resources Research ، 7(5): 1051-1063.

8. Dudley، N. J.6 D. T. Howell and W. D. Musgrave(1971،b). "Irrigation planning 3: The best size of irrigation area for a reservoir". Water Resources Research ، 8(1): 7-17

9. Dudley، N. J. (1972). "Irrigation planning 4:Optimal intraseasonal water allocation". Water Resources Research، 8(3)586-594.

10.English، M. J. and S. N. Raja (1996). "Review prespective on deficit irrigation". Agriculture Water Management 32: 1-14.

11.Francesco، M. and P. Mecarelli (1994). "Optimization of deficit irrigation". Journal of the Irrigation and Drainage Division، ASCE 126(3): 484-503.

12.Gorantiwar' S. D. and I. K. Smout (2003). "Allocation of scare water resources using deficit irrigation in rotational systems". Journal of the Irrigation and Drainage Division، ASCE، 129(3): 155-163.

13.Gorantiwar، S. D. and I. K. Smout (2005) "Multilevel approach for optimizing land and water resources and irrigation deliveries for tertiary under irrigation schemes II:Application". Journal of the Irrigation and Drainage Division، ASCE، 131(3): 264-272. 
14.Kumar، C. N. ‘ N. Indrasenan، and K. Elango (1998). "Nonlinear programming model for extensive irrigation". Journal of the Irrigation and Drainage Division، ASCE، 124(2): 123-126.

15.Martin D. L . J. Brocklin and G. Wilmes (1989). "Operating rules for deficit irrigation". Trans. ASAE 32(4):1207-1215.

16.Paul، S. S. M. Panda and D. N. Kumar (2000). "Optimal irrigation allocation ' a multilevel approach". Journal of the Irrigation and Drainage Division ASCE. 126(3): 149-156.

17.Rao، N. H. ، P. B. S. Sarma and S. Chander (1990). "Optimal multicrop allocation of seasonal and intraseasonal irrigation water". Water Resources Research ، 26(4): 551-559. 
الاباغ: التخصيص الامثل للمياه الفصلية بين مجموعة محاصيل تحت محدودية توفر مياه الري 